\title{
Characterization of Streptomycetes Causing Deep-Pitted Scab of Potato in Québec, Canada
}

\author{
ESTHER FAUCHER, ${ }^{1}$ ERIC PARADIS, ${ }^{1}$ CLAUDIA GOYER, ${ }^{1}$ NANCY C. HODGE,${ }^{2}$ RICHARD HOGUE, ${ }^{3}$ \\ ROBERT E. STALL, ${ }^{2}$ AND CAROLE BEAULIEU ${ }^{1 *}$ \\ Groupe de Recherche en Biologie des Actinomycètes, Département de Biologie, Université de Sherbrooke, Sherbrooke, \\ Québec, Canada J1K 2R1 ${ }^{1}$; Department of Plant Pathology, University of Florida, Gainesville, Florida 32611 \\ and Service de Phytotechnie de Québec, Sainte-Foy, Québec, Canada G1P $3 W 8^{3}$
}

\begin{abstract}
Nine streptomycete strains that cause deep-pitted scab of potato were characterized by performing 138 physiological and morphological tests. A numerical analysis revealed that the deep-pitted scab-inducing organisms were related to strains belonging to cluster 1 of Williams et al. (Streptomyces albidoflavus). The levels of similarity between the deep-pitted scab-inducing strains and strains of Streptomyces scabies and Streptomyces acidiscabies were low (52 and 54\%, respectively). The fatty acid profiles of the deep-pitted scab-inducing organisms differed considerably from those of $S$. scabies and $S$. acidiscabies. The deep-pitted scab-inducing bacteria were characterized by the predominance in their profiles of the 15:0 anteiso, 15:0 iso, 16:0 iso, 16:0, and 17:0 anteiso acids. The results of physiological characterization experiments, a fatty acid analysis, and whole-cell protein electrophoresis showed that the deep-pitted scab-inducing strains characterized in this study formed a relatively homogeneous group. These pathogenic strains could also be differentiated from $S$. scabies by their high cellulolytic and proteolytic activities.
\end{abstract}

Potato scab is an economically important disease in eastern Canada (8), and potato scab that is characterized by shallow or deep corky lesions is observed mostly on tubers. This disease is caused by several Streptomyces species, but Streptomyces scabies is the predominant causal agent. Lambert and Loria (7) characterized $S$. scabies as having smooth gray spores borne in spiral chains, producing melanin, and utilizing sucrose, L-arabinose, fructose, glucose, mannitol, raffinose, L-rhamnose, and D-xylose.

Unlike $S$. scabies, Streptomyces acidiscabies, an acid-tolerant species, can induce potato scab symptoms in acid soils (6). The primary characteristics of $S$. acidiscabies are the production of white spores borne in flexuous chains, the inability to synthesize melanoid pigments, and the ability to utilize sucrose, Larabinose, fructose, glucose, mannitol, L-rhamnose, and D-xylose but not raffinose (6).

The characteristics of numerous potato scab-inducing organisms are not consistent with the description of $S$. scabies or $S$. acidiscabies. Archuleta and Easton (1) identified four actinomycete species (Streptomyces diastatochromogenes, Streptomyces atroolivaceus, Streptomyces lydicus, and Streptomyces resistomycificus) as causal agents of deep-pitted scab in the state of Washington. Doering-Saad et al. (3) divided potato scab-inducing strains into three phenotypic groups, and the pathogenic strains of the three groups exhibited diverse morphological characteristics. Spore chain morphology ranged from spiral to flexuous to retinaculum-apertum to rectus, and spore ornamentation ranged from smooth to warty to spiny. Doering-Saad et al. (3) included in their study pathogenic strains from Israel that cause deep-pitted scab in irrigated fields. No correlation was found between the severity of symptoms (shallow scab versus deep-pitted scab) and the clustering of the pathogenic strains.

We previously described three groups of causal agents of

\footnotetext{
* Corresponding author. Mailing address: Département de Biologie, Université de Sherbrooke, Sherbrooke (Qué), Canada, J1K 2R1. Phone: (819) 821-7997. Fax: (819) 821-8049. Electronic mail address: C.BEAULI@COURRIER.USHERB.CA.
}

potato scab in Québec, Canada: $S$. scabies, $S$. acidiscabies, and an unidentified Streptomyces species which was characterized by gold to light brown colonies on yeast extract-malt extract agar, white spores borne in flexuous chains, a lack of melanoid pigment production, resistance to streptomycin, and utilization of raffinose as a sole carbon source (4). This species was associated only with deep-pitted scab and was most commonly isolated from irrigated soil. It was abundant in the SaguenayLac St-Jean area, but was also infrequently isolated in other areas of the province of Québec. The purpose of this study was to characterize isolates of this species.

\section{MATERIALS AND METHODS}

Bacterial strains and culture media. The following nine deep-pitted scabinducing strains were characterized in this study: EF-83, EF-86, EF-87, EF-88, EF-92, EF-95, EF-98, EF-104, and EF-123. The bacteria were routinely propagated on yeast extract-malt extract agar (12). Streptomycetes were grown for 3 to 9 days in $125 \mathrm{ml}$ of fatty acid-free Trypticase soy broth (BBL) prior to fatty acid analysis. To obtain cultures for electrophoretic analysis of soluble proteins, strains were grown in $\mathrm{YGM}^{+}$medium (5).

Physiological and morphological characterization. The nine deep-pitted scabinducing strains were characterized by performing the 138 physiological and morphological tests used by Williams et al. (14) to divide Streptomyces strains into 59 clusters. A numerical analysis was carried out as described by Lambert and Loria (6). Strain characteristics that exist in one of two mutually exclusive states were scored as either plus $(100)$ or minus $(0)$. For qualitative multistate characteristics (spore color, spore chain morphology, spore ornamentation, and colony color), chosen properties were given a value of 100 (positive), and any alternative was given a value of 0 (negative). These values were averaged by trait to form group composites for the nine deep-pitted scab-inducing strains. To determine the levels of similarity between this group of microorganisms and the clusters of Williams et al., differences in the values for each trait were added and then divided by the number of traits examined. The resulting number was subtracted from 100 to obtain the percentage of similarity.

Similar studies were performed to compare the deep-pitted scab-inducing strains with $S$. scabies and $S$. acidiscabies strains. However, in this case, the physiological and morphological tests used to compare the bacterial groups were the tests described by Lambert and Loria $(6,7)$. Ten $S$. scabies strains (EF-5, EF-35, EF-46, EF-49, EF-54, EF-58, EF-63, EF-64, EF-68, and EF-84) isolated in Québec by Faucher et al. (4) and four $S$. acidiscabies strains (EF-9, EF-12, EF-81, and ATCC $49003^{\mathrm{T}}$ [T = type strain]) were compared with the nine deep-pitted scab-inducing strains.

Fatty acid analysis. A fatty acid analysis was performed with the nine deeppitted scab-inducing strains, S. scabies EF-35 (4) and 89-19 (5), and S. acidiscabies ATCC $49003^{\mathrm{T}}$. Fatty acids were analyzed by using cultures in the mid-log 
TABLE 1. Levels of similarity between deep-pitted scab-inducing strains and selected clusters of Williams et al. ${ }^{a}$

\begin{tabular}{llc}
\hline Cluster & \multicolumn{1}{c}{ Cluster name } & $\begin{array}{c}\% \\
\text { Similarity }\end{array}$ \\
\hline 1 & Streptomyces albidoflavus & 75.8 \\
9 & Streptomyces californicus & 74.1 \\
10 & Streptomyces fulvissimus & 74.1 \\
42 & Streptomyces rimosus & 73.5 \\
5 & Streptomyces exfoliatus & 73.4 \\
7 & Streptomyces roseus & 72.7 \\
6 & Streptomyces violaceus & 72.2 \\
29 & Streptomyces lydicus & 71.6 \\
40 & Streptomyces phaeochromogenes & 71.6 \\
3 & Streptomyces atroolivaceus & 71.1 \\
19 & Streptomyces diastaticus & 70.6 \\
21 & Streptomyces griseoruber & 70.6 \\
64 & Streptomyces bikiniensis & 70.2 \\
15 & Streptomyces chromofuscus & 70.0 \\
\hline
\end{tabular}

${ }^{a}$ See reference 14

${ }^{b}$ The table includes clusters which exhibit at least $70 \%$ similarity to the deep-pitted scab-inducing organisms.

phase of growth. Cultures were passed through cellulosic $0.45-\mu \mathrm{m}$-pore-size filters, and approximately $40-\mathrm{mg}$ (wet weight) portions of cells were transferred to glass test tubes ( 13 by $100 \mathrm{~mm}$ ) which were fitted with Teflon-lined caps for fatty acid extraction. Cellular fatty acids were extracted and derivatized to their methyl esters as described by Miller (10). Several strains were extracted in duplicate to assess the reproducibility of the derivatization technique, as well as the gas chromatographic system. A statistical analysis of the fatty acid methyl ester profiles was performed by using the MIDI Library Generation System software (Midi, Newark, Del.)

Whole-cell protein analysis. The methods used for extraction of soluble proteins, protein electrophoresis, and densitometric analysis of electropherograms have been described previously (11).

Pectinolytic, amylolytic, cellulolytic, and proteolytic activities. The method used to detect pectinolytic activity has been described previously (2). To determine amylolytic, cellulolytic, and proteolytic activities, suspensions containing $10^{6}$ spores of each of $10 \mathrm{~S}$. scabies strains and nine deep-pitted scab-inducing strains were inoculated in the centers of yeast extract-malt extract agar plates containing $1 \%$ starch, $1 \%$ carboxymethyl cellulose, and 5\% skim milk (Difco), respectively. The diameters of the clearing zones were determined after incubation at $30^{\circ} \mathrm{C}$ for 5,6 , and 7 days; the tests were repeated five times.

\section{RESULTS}

Numerical taxonomy. Table 1 shows the levels of similarity (based on phenotypic characteristics) between organisms causing deep-pitted scab and strains belonging to the clusters of Williams et al. The deep-pitted scab-inducing group showed exhibited the highest level of similarity $(76 \%)$ with cluster 1 of Williams et al. (Streptomyces albidoflavus). We observed low levels of similarity between the deep-pitted scab-inducing strains and strains of $S$. scabies and $S$. acidiscabies (52 and 54\%, respectively).

Fatty acid analysis. The fatty acid profiles of the deep-pitted scab-inducing organisms consisted of 12 to 18 acids, most of which were branched iso and anteiso acids. Unsaturated fatty acids were not prevalent, accounting for less than $4 \%$ of the total fatty acids. The profiles were characterized by a predominance of $15: 0$ anteiso acid ( 30 to $35 \%$ of the total fatty acids) and 15:0 iso, 16:0 iso, 16:0, 17:0 anteiso acids, each of which accounted for 9 to $15 \%$ of the total fatty acids (Table 2). The strains clustered within a Euclidian distance of 4.5 , indicating that they were probably members of the same species. $S$. scabies 89-19 and EF-5, S. acidiscabies ATCC $49003^{\mathrm{T}}$, and the deep-pitted scab-inducing strains clustered within a Euclidian distance of 25 , indicating that all of these strains are probably members of the same genus (Fig. 1).
TABLE 2. Fatty acid compositions of different streptomycete groups

\begin{tabular}{lrrrr}
\hline & \multicolumn{4}{c}{ \% of total fatty acids in: } \\
\cline { 2 - 5 } Fatty acid & $\begin{array}{c}\text { Deep-pitted } \\
\text { scab-inducing } \\
\text { strains }\end{array}$ & $\begin{array}{c}\text { S. scabies } \\
89-19 \\
\text { (fatty } \\
\text { acid } \\
\text { group 1) }\end{array}$ & $\begin{array}{c}\text { S. scabies } \\
\text { EF-5 } \\
\text { (fatty } \\
\text { acid } \\
\text { group 2) }\end{array}$ & $\begin{array}{c}\text { S. acidiscabies } \\
\text { ATCC } \\
49003^{\text {Tb }}\end{array}$ \\
\hline $13: 0$ iso & $0.14(0.14)$ & 1.15 & 0.86 & 0.72 \\
$14: 0$ iso & $3.44(0.68)$ & 1.15 & 2.60 & 1.80 \\
$14: 0$ & $0.65(0.17)$ & 2.70 & 1.49 & 4.50 \\
$15: 0$ iso & $10.54(1.26)$ & 13.59 & 19.94 & 9.00 \\
$15: 0$ anteiso & $32.97(1.79)$ & 16.53 & 19.89 & 19.73 \\
$15: 0$ & $1.88(0.14)$ & 2.50 & 1.43 & 1.80 \\
$16: 0$ iso & $13.43(1.96)$ & 7.82 & 9.18 & 2.31 \\
$16: 1$ cis 9 & $2.86(0.49)$ & 10.12 & 3.91 & 19.39 \\
$16: 0$ & $11.02(1.17)$ & 28.05 & 21.79 & 37.30 \\
$17: 1$ iso F & $1.36(0.91)$ & 1.72 & 2.05 & 0.00 \\
$17: 1$ anteiso C & $0.92(0.22)$ & 0.66 & 0.71 & 0.00 \\
$17: 0$ iso & $5.50(0.57)$ & 4.17 & 7.94 & 1.09 \\
$17: 0$ anteiso & $12.95(1.17)$ & 5.72 & 6.39 & 2.35 \\
$17: 0$ & $0.92(0.12)$ & 0.83 & 0.50 & 0.00 \\
\hline
\end{tabular}

${ }^{a}$ Average fatty acid composition of nine strains. The numbers in parentheses are standard deviations.

${ }^{b}$ Means of the values obtained from two experiments.

Whole-cell protein electrophoresis. An analysis of whole-cell soluble protein electropherograms in which the unweighted pair group with arithmetic average method was used revealed that the deep-pitted scab-inducing organisms form a relatively homogeneous group, with an average correlation coefficient of 0.84. However, strains EF-98 and EF-104 exhibited more diversity in their protein profiles than the other deep-pitted scabinducing strains. The average correlation coefficients between strains EF-98 and EF-104 and the other deep-pitted scabinducing strains were 0.78 and 0.77 , respectively (Table 3 ).

Pectinolytic, amylolytic, cellulolytic, and proteolytic activities. None of the strains used in this study produced extracel-

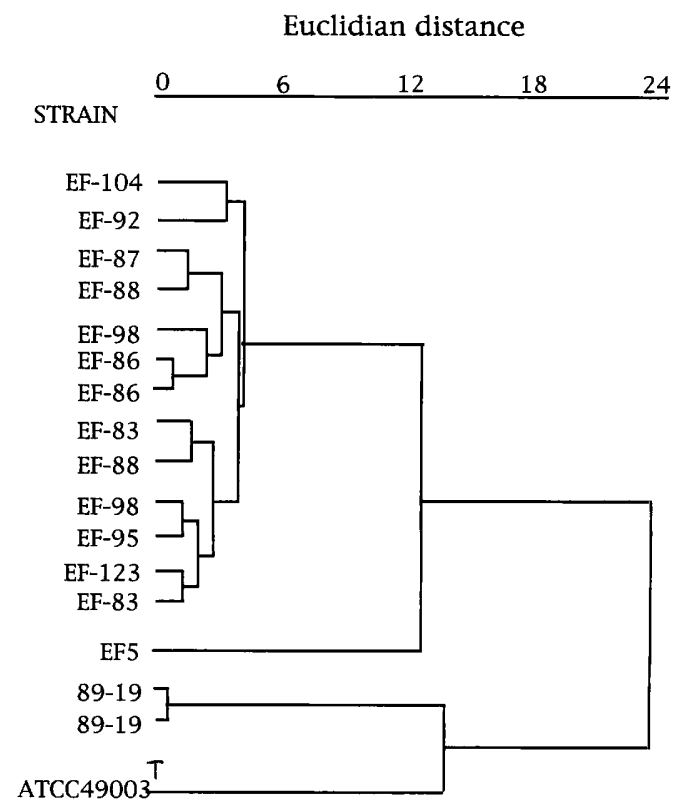

FIG. 1. Dendrogram showing the levels of fatty acid relatedness among different streptomycete groups. 
TABLE 3. Correlation coefficients for the protein profiles of nine deep-pitted scab-inducing strains

\begin{tabular}{llllllllll}
\hline \multirow{2}{*}{ Strain } & \multicolumn{8}{c}{ Correlation coefficient with: } \\
\cline { 2 - 9 } & EF-83 & EF-86 & EF-87 & EF-88 & EF-92 & EF-95 & EF-98 & EF-104 & EF-123 \\
\hline EF-83 & 0.98 & & & & & & & \\
EF-86 & 0.95 & 0.94 & & & & & & \\
EF-87 & 0.94 & 0.90 & 1.00 & & & & & & \\
EF-88 & 0.87 & 0.78 & 0.89 & 1.00 & & & & & \\
EF-92 & 0.93 & 0.88 & 0.92 & 0.93 & 1.00 & & & & \\
EF-95 & 0.88 & 0.82 & 0.84 & 0.76 & 0.80 & 0.98 & & & \\
EF-98 & 0.84 & 0.78 & 0.77 & 0.78 & 0.82 & 0.77 & 0.93 & & \\
EF-104 & 0.79 & 0.73 & 0.83 & 0.81 & 0.82 & 0.60 & 0.74 & 1.00 & \\
EF-123 & 0.92 & 0.79 & 0.92 & 0.90 & 0.88 & 0.98 & 0.76 & 0.80 & 1.00 \\
\hline
\end{tabular}

lular pectinases under the conditions described previously. $S$. scabies strains, as well as deep-pitted scab-inducing strains, exhibited high amylolytic activities. High cellulolytic activities were usually associated with deep-pitted scab-inducing strains, even though most $S$. scabies strains produced cellulases. Proteolytic activities were associated only with deep-pitted scabinducing bacteria (Fig. 2).

\section{DISCUSSION}

Archuleta and Easton (1) suggested that most cases of deeppitted scab in the state of Washington should not be attributed to $S$. scabies but should be attributed to four other Streptomyces species. Unfortunately, this suggestion has never been confirmed, and none of the isolates of Archuleta and Easton is available for examination. In Québec, a group of bacteria isolated from deep-pitted scab lesions of potatoes grown in irrigated soil also exhibited numerous traits that are not characteristic of $S$. scabies, such as production of white spores borne in flexuous chains, a lack of melanoid pigment production, and resistance to streptomycin (4). Phenotypic characterization, fatty acid analysis, and whole-cell protein electrophoresis revealed that these plant-pathogenic bacteria formed a relatively homogeneous group. These studies also suggested that the deep-pitted scab-inducing strains in Québec were not $S$. scabies or $S$. acidiscabies strains. The levels of similarity between the deep-pitted scab-inducing strains and $S$. scabies and $S$. acidiscabies strains based on morphological and physiological properties were low ( 52 and $54 \%$, respectively). The fatty acid profiles of these three groups of plant pathogens were also very different. The deep-pitted scab-inducing strains clustered within a Euclidian distance of 16.5 with $S$. acidiscabies and within Euclidian distances of 16.0 and 16.5 with $S$. scabies strains belonging to fatty acid groups 1 and 2 , respectively (11).

A relatively high level of similarity, $76 \%$, was found between the phenotypic traits of these plant-pathogenic bacteria from Québec and the phenotypic traits of strains belonging to cluster 1 of Williams et al. This was the highest level of similarity found between the diverse clusters of Williams et al. and the deep-pitted scab-inducing bacteria. According to the criteria of Williams et al., a similarity level of $76 \%$ is not high enough to classify two bacterial groups in the same cluster. In their study, a level of similarity of $78 \%$ was required to consider two strains members of the same cluster. Interestingly, the deep-pitted scab-inducing bacteria also exhibited a relatively high level of similarity to Streptomyces lydicus (cluster 29 of Williams et al.), one of the four species identified by Archuleta and Easton (1) as a causal agent of deep-pitted scab in the state of Washington.

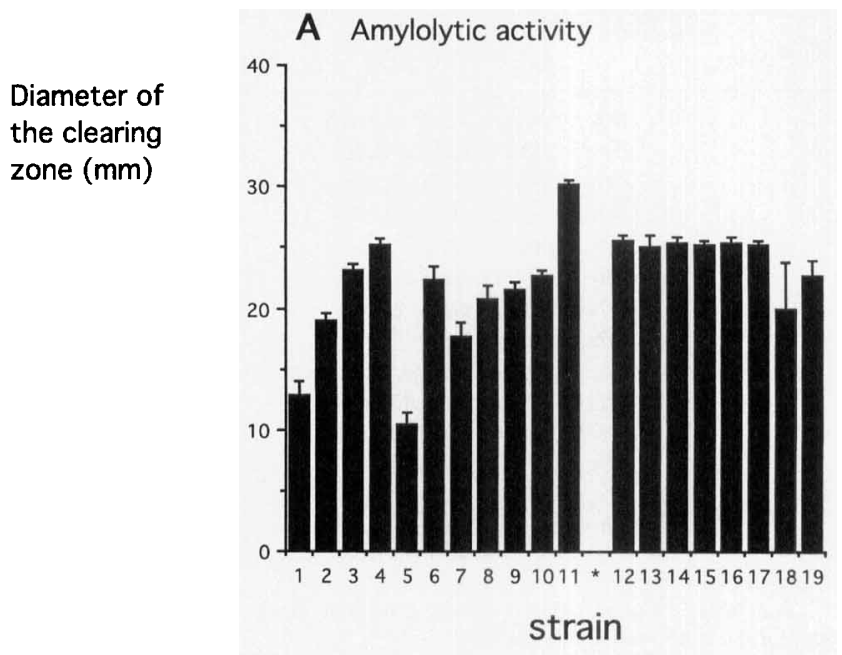

Diameter of
the clearing
zone $(\mathrm{mm})$

B Cellulolytic activity
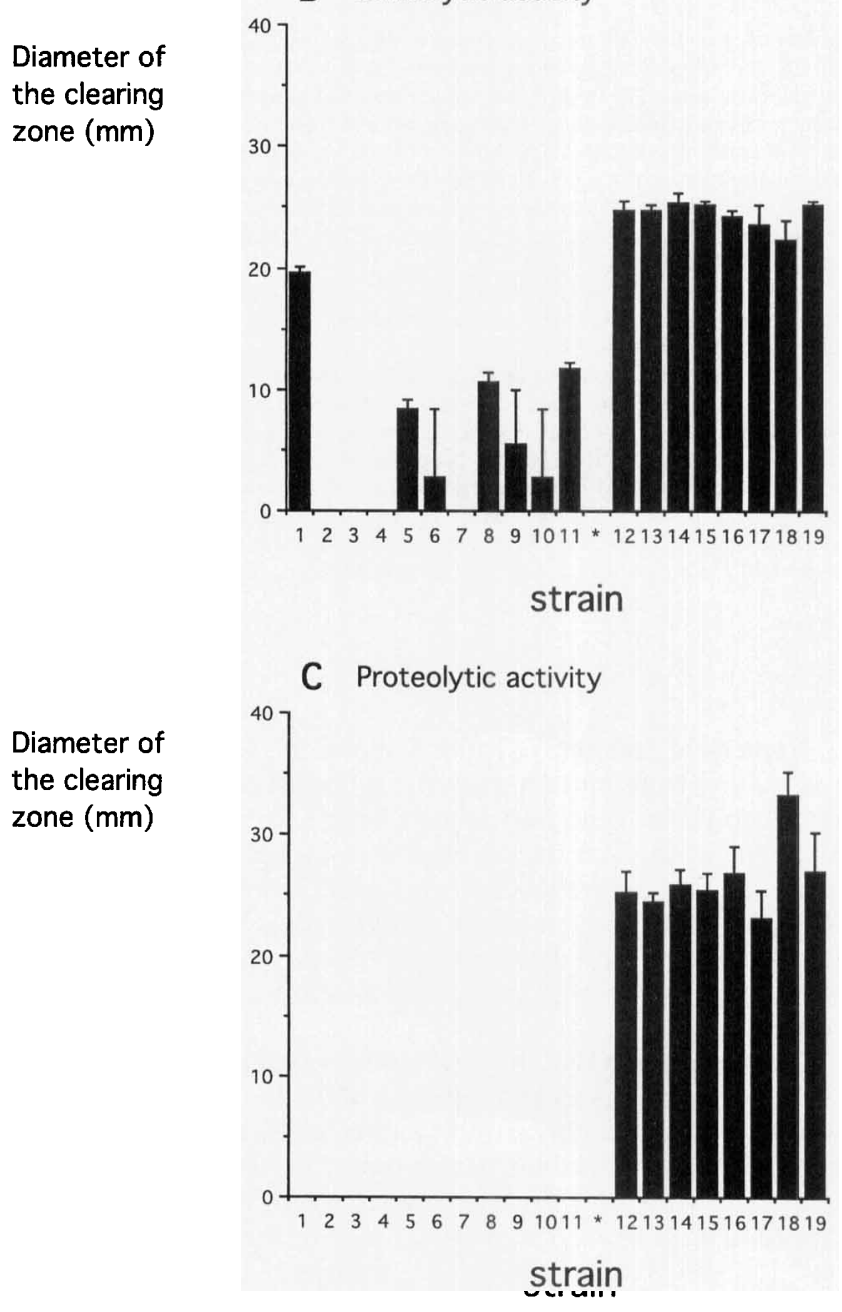

FIG. 2. Amylolytic (A), cellulolytic (B), and proteolytic (C) activities of $S$. scabies EF-2 (strain 1), EF-5 (strain 2), EF-35 (strain 3), EF-58 (strain 4), EF-63 (strain 5), EF-64 (strain 6), EF-77 (strain 7), EF-84 (strain 8), EF-90 (strain 9), $\mathrm{EF}-127$ (strain 10), and 89-19 (strain 11) and of deep-pitted scab-inducing strains EF-83 (strain 12), EF-86 (strain 13), EF-87 (strain 14), EF-88 (strain 15), EF-92 (strain 16), EF-98 (strain 17), EF-104 (strain 18), and EF-123 (strain 19). 
Workers should not conclude that deep-pitted scab is associated only with the microorganisms described in this study. Under some circumstances, S. scabies strains can also induce deep-pitted scab of potato (4). The severity of symptoms caused by $S$. scabies depends on the interaction among cultivar resistance, environmental conditions, and bacterial virulence. Moreover, in Israel, where problems with deep-pitted scab in irrigated soil are encountered frequently, no correlation has been found between the severity of symptoms on tubers and phenotypic classification of pathogenic strains (3).

The role of hydrolytic enzymes in common scab has not been evaluated in detail. Spooner and Hammerschmidt (13) demonstrated that the production of extracellular pectinases was not correlated with pathogenicity for potatoes for Streptomyces species. Conversely, McQueen and Schottel (9) suggested that an extracellular esterase from $S$. scabies is involved in pathogenicity. The mechanisms associated with the severe symptoms caused by the strains described in this study are still not known. However, in contrast to most $S$. scabies strains, the deep-pitted scab-inducing strains exhibited high proteolytic and cellulolytic activities. Studies to determine the role of these enzymes during pathogenesis are being performed.

\section{ACKNOWLEDGMENTS}

We thank G. G. Grondin for technical assistance, C. Déry for critically reading the manuscript, and $\mathrm{C}$. $\mathrm{H}$. Lawrence for giving us bacterial strains.

This work was supported by a grant from the Natural Sciences and Engineering Research Council of Canada. C.G. gratefully acknowledges a scholarship from the Fonds pour la formation des chercheurs et l'aide à la recherche du gouvernement du Québec.

\section{REFERENCES}

1. Archuleta, J. G., and G. D. Easton. 1981. The cause of deep-pitted scab. Am. Potato J. 58:385-393.

2. Beaulieu, C., and F. Van Gijsegem. 1990. Identification of plant-inducible genes in Erwinia chrysanthemi 3937. J. Bacteriol. 172:1569-1575.

3. Doering-Saad, C., P. Kämpfer, M. Shulamit, G. Kritzman, J. Schneider, J. Zakrewska-Czerwinska, H. Schrempf, and I. Barash. 1992. Diversity among Streptomyces strains causing potato scab. Appl. Environ. Microbiol. 58:39323940.

4. Faucher, E., T. Savard, and C. Beaulieu. 1992. Characterization of actinomycetes isolated from common scab lesions on potato tubers. Can. J. Plant Pathol. 14:197-202.

5. King, R. R., C. H. Lawrence, and M. C. Clark. 1991. Correlation of phytotoxin production with pathogenicity of Streptomyces scabies isolates from scab infected potato tubers. Am. Potato J. 68:675-680.

6. Lambert, D. H., and R. Loria. 1989. Streptomyces acidiscabies sp. nov. Int. J. Syst. Bacteriol. 39:393-396.

7. Lambert, D. H., and R. Loria. 1989. Streptomyces scabies sp. nov., nom. rev. Int. J. Syst. Bacteriol. 39:387-392.

8. Lawrence, C. H. 1964. Gale commune de la pomme de terre. Agriculture Canada publication 953. Agriculture Canada, Ottawa, Canada.

9. McQueen, D. A. R., and J. L. Schottel. 1987. Purification and characterization of a novel extracellular esterase from pathogenic Streptomyces scabies that is inducible by zinc. J. Bacteriol. 169:1967-1971.

10. Miller, L. T. 1982. Single derivatization method for routine analysis of bacterial whole-cell fatty acid methyl esters, including hydroxy acids. J. Clin. Microbiol. 16:584-586.

11. Paradis, E., C. Goyer, N. C. Hodge, R. Hogue, R. E. Stall, and C. Beaulieu. 1994. Fatty acid and protein profiles of Streptomyces scabies strains isolated in eastern Canada. Int. J. Syst. Bacteriol. 44:561-564.

12. Pridham, T. G., P. Anderson, C. Foley, L. A. Lindenfelser, C. W. Hessetine, and R. G. Benedict. 1956-1957. A selection medium for maintenance and taxonomic study of streptomycetes. Antibiot. Annu. 1956-57:947-953.

13. Spooner, F. R., Jr., and R. Hammerschmidt. 1989. Characterization of extracellular pectic enzymes produced by Streptomyces species. Phytopathology 79:1190.

14. Williams, S. T, M. Goodfellow, G. Alderson, E. M. H. Wellington, P. H. A Sneath, and M. J. Sackin. 1983. Numerical classification of Streptomyces and related genera. J. Gen. Microbiol. 129:1743-1813. 